\title{
Recent Advances in Studies on Guillain-Barre Syndrome: Correlation Between Microorganisms and New Treatment Perspectives
}

\author{
Thaís Cristine Pereira ${ }^{1 *}$, Pâmela Beatriz do Rosário Estevam dos Santos ${ }^{1}$, Vivian Cristina Costa Castilho \\ Hyodo $^{2}$ \\ ${ }^{1}$ Department of Biosciences and Oral Diagnosis, Institute of Science and Technology, Brazil \\ ${ }^{2}$ Paulista University (UNIP), Institute of Health Sciences, Brazil
}

*Corresponding author: Thaís Cristine Pereira, São Paulo State University (UNESP). Institute of Science and Technology. Department

of Biosciences and Oral Diagnosis. São José dos Campos, São Paulo 12245-000, Brazil

\section{ARTICLE INFO}

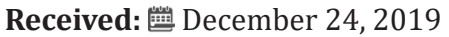

Published: 幽January 07, 2020

\section{ABSTRACT}

Citation: Thaís Cristine Pereira, Pâmela Beatriz do Rosário Estevam dos Santos, Vivian Cristina Costa Castilho Hyodo. Recent Advances in Studies on Guillain-Barre Syndrome: Correlation Between Microorganisms and New Treatment Perspectives. Biomed J Sci \& Tech Res 24(3)-2020. BJSTR. MS.ID.004040.

\section{Introduction}

The Guillain-Barré Syndrome (GBS) is a postinfectious and autoimmune-induced peripheroneural disorder characterized by being an acquired acute inflammatory demyelinating polyradiculoneuropathy which often follows gastrointestinal or respiratory infections [1-3]. This rare and fatal pathology is characterized by a progressive bilateral and symmetric ascending limbs weakness (classic form) that may present areflexia or hyporeflexia, elevated cerebrospinal fluid protein without pleocytosis, and may or may not have sensory involvement [1-4]. The clinical and electrophysiological spectrum of GBS may include other clinical variants, such as Miller-Fisher syndrome, as well as some autonomic disorders such as tachycardia or bradycardia, hypertension or hypotension, excessive or nonexistent sweating, and urinary retention [2-4].

This autoimune disorder involves humoral as well as cellmediated immune mechanisms, but the exact cause of the disease is not yet fully understood [2-5]. Several microorganisms (such as bacteria and viruses) are known to be associated with the infections prior to GBS. In Brazil, there is a correlation of the disease with arboviruses, and there are reports of GBS as sequelae after patients acquire Dengue, Chikungunya, and Zika virus [6]. Given this, with the increase of this syndrome worldwide, researchers are looking for new more effective treatment alternatives and with less adverse effects on patients $[7,8]$

\section{Microorganisms}

A wide range of infections can precede the GBS with several pathogens that affect patients around the world. One of the most recurrent microorganisms associated with infections prior to GBS is Campylobacter jejuni, a common pathogen that causes food-borne infections and may be associated with ingestion of undercooked poultry or even the contact with farm animals [9]. The Mycoplasma pneumoniae species is a common cause of respiratory infections (upper and lower respiratory tract) and may also be related to the GBS and many other clinical complications, such as encephalitis, and meningitis, among others [9,10]. Haemophilus influenzae, which usually colonizes the nasopharynx, causes respiratory infections [9-11]. Several virus infections may also participate in the development of GBS: Cytomegalovirus, an ubiquitous pathogen that can lead to severe diseases such as pneumonitis, encephalitis, and retinitis in immunosuppression conditions [9-12]. Varicella Zoster Virus (VZV) is also related, being a human neurotropic alphaherpesvirus [9-13]. Epstein-Barr virus infections associated with the host immune response promotes the clinical manifestation known as mononucleosis; Hepatitis viruses that affect the liver 
and are some of the most widespread human pathogens, may also precede GBS as well as the Human Immunodeficiency Virus (HIV) which progressively leads to an immune deficiency that manifests with the appearance of life-threatening opportunistic infections $[9,14-16]$.

Dengue, Zika and Chikungunya are viruses that cause similar diseases which symptoms are nonspecific and overlap, [17] and all of them can be transmitted by mosquito bites: Dengue is characterized by high fever, arthralgia, myalgia, anorexia, petechiae/rash, and retro-orbital pain [9,17]. Zika virus infections are usually asymptomatic (60-80\% of cases), although when the clinical symptoms appear they may include low fever, arthralgia, conjunctivitis and maculopapular rash $[9,18,19]$. Symptomatic Chikungunya infections present the clinical conditions of acute fever-arthralgia syndrome, which may progress to chronic and debilitating inflammatory rheumatism $[9,20]$.

Like the previously mentioned pathogens, these viruses can be found in different countries; however, they are very prominent in Brazil, not only for the diseases they cause, but also for their association with GBS.

\section{Guillain-Barre Syndrome in Brazil}

In Brazil, the high rate of GBS diagnosed in recent years may be related to Dengue, Chikungunya and Zika virus (DCZ). The prevalence of these arboviruses is due to the favorable conditions for the development of vectors that can transmit them, and consequently spread these diseases [21]. The correlation between GBS and arbovirus diseases prevalent in Brazil has been associated as a sequel after manifestations of these viruses in patients. 6 In this country, Dengue cases have been prevalent for many years, but until 2014 there was no significant increase in reports of GBS. However, after this period, there was the introduction of Zika virus in Brazil, and there was a significant increase in GBS cases, worrying the Health Departments of the country [22,23]. Given the above, detailed studies were performed, the information was collected from suspected, probable, confirmed and discarded cases, and later, they collected data from the patients analyzing whether they had acquired previous infections with DCZ. Data from several surveys showed that Brazil would need a national protocol for investigating GBS following infections caused by DCZ. The results showed a possible correlation between GBS and Zika vírus, since there were no outbreaks of the disease before the circulation of this virus was registered [23].

This correlation is reported in several studies, patients diagnosed with GBS had Zika virus-neutralizing antibodies, thus confirming this specific relationship between cases [23-25]. In addition to Brazil, outbreaks of GBS associated with Zika virus infections were diagnosed in French Poland in 2013 [26]. Despite many reports involving Zika virus, there are publications of neurological manifestations which were also caused by Dengue
[27]. The etiopathogenesis of GBS after Dengue is still rare and poorly described [1]. Even though this correlation is an uncommon sequel, there are reports in the clinical literature and this association should be further investigated [1-6].

Chikungunya virus can also cause infections and evolve into severe neurological conditions, up to $60 \%$ of cases of severe atypical neurological complications of Chikungunya infection have been reported [28]. However, according to the literature most cases of GBS are associated with cases of infections caused by Zika virus. 6 In Brazil and other tropical countries, DCZ certainly play an important role in GBS [29]. With the increasing incidence of GBS in Brazil and worldwide, it is extremely important to investigate new treatment alternatives, thus avoiding irreversible or fatal cases.

\section{New Perspectives of Treatment}

The conventional effective treatments for GBS are intravenous immunoglobulin and plasma exchange, the former being the first treatment choice due to easy application, availability and minor side effects [7,30-31] Although these treatments are the most used, many patients may not respond well to them and have limited mobility, pain and fatigue, and in some cases even pass away, so these treatments should be administered as soon as possible for them to be more effective and prevent further nerve damage $[32,33]$. Currently, the development of new treatment alternatives is still very scarce. Given the above, there is a need for studies that can investigate more modern treatments.

A new treatment alternative, called the Zipper Method, can reduce mortality, accelerate weaning from mechanical ventilation, and decrease length of stay. This method consists of a combined administration of the two conventional methods, administering plasma exchange and subsequently intravenous infusion of immunoglobulin, than repeating the process around five times. This method may be promising, but it needs further clinical studies to prove its efficacy [7]. Some therapeutic biological agents have also attracted the attention of researchers [8]. These agents are protein drugs that mediate their effects by modulating the immune system [34]. These biological drugs have been reported to be effective for treating GBS, but more clinical studies are needed. Advances in medicine are essential for a better understanding of the immunopathology of the disease in order to identify new therapeutic targets [8].

\section{Conclusion}

The increase in GBS cases in Brazil and worldwide has led to several studies to better understand the correlation between microorganisms and the syndrome and develop new treatment alternatives, as conventional therapies may have adverse effects on patients. Although there are publications in the clinical literature of new therapeutic strategies, it is extremely important to develop more studies in order to prove them. 


\section{References}

1. Dalugama C, Shelton J, Ekanayake M, Gawarammana IB (2018) Dengue fever complicated with Guillain-Barré syndrome: a case report and review of the literature. J Med Case Rep 12(1): 137.

2. Konuşkan B, Okuyaz Ç, Taşdelen B, Kurul SH, Anlar B (2018) Electrophysiological Subtypes and Prognostic Factors of Childhood Guillain-Barré Syndrome. Noro Psikiyatr Ars 55(3): 199-204.

3. Liu H, Ma Y (2019) Hepatitis E virus-associated Guillain-Barre syndrome: Revision of the literature. Brain Behav 11: e01496.

4. Leung J, Sejvar JJ, Soares J, Lanzieri TM (2019) Guillain-Barré syndrome and antecedent cytomegalovirus infection, USA 2009-2015. Neurol Sci.

5. Wajih Ullah M, Qaseem A, Amray A (2018) Post Vaccination Guillain Barre Syndrome: A Case Report. Cureus 10(4): e2511.

6. Lima MES, Bachur TPR, Aragão GF (2019) Guillain-Barre syndrome and its correlation with dengue, Zika and chikungunya viruses infection based on a literature review of reported cases in Brazil. Acta Trop 197: 105064.

7. Kesici S, Tanyıldız M, Yetimakman F, Bayrakci B (2019) A Novel Treatment Strategy for Severe Guillain-Barré Syndrome: Zipper Method. J Child Neurol (5): 277-283.

8. Motamed-Gorji N, Matin N, Tabatabaie $\mathrm{O}$, Pavone $\mathrm{P}$, Romano $\mathrm{C}$, et al. (2017) Biological Drugs in Guillain-Barré Syndrome: An Update. Curr Neuropharmacol 15(7): 938-950.

9. Rodríguez Y, Rojas M, Pacheco Y, Acosta-Ampudia Y, Ramírez-Santana C, et al. (2018) Guillain-Barré syndrome, transverse myelitis and infectious diseases. Cell Mol Immunol 15(6): 547-562.

10. Parrott GL, Kinjo T, Fujita J (2016) A Compendium for Mycoplasma pneumoniae. Front Microbiol 7: 513

11. Dong Q, Shi W, Cheng X, Chen C, Meng Q et al. (2019) Widespread of nontypeable Haemophilus influenzae with high genetic diversity after two decades use of Hib vaccine in China. J Clin Lab Anal 17: e23145.

12. Svrlanska A, Ruhland A, Marschall M, Reuter N, Stamminger T (2019) Wedelolactone inhibits human cytomegalovirus replication by targeting distinct steps of the viral replication cycle. Antiviral Res 10: 104677.

13. Nagel MA, Jones D, Wyborny A (2017) Varicella zoster virus vasculopathy The expanding clinical spectrum and pathogenesis. J Neuroimmunol 308: 112-117.

14. Jenson HB (2011) Epstein-Barr virus. Pediatr Rev 32(9): 375-383.

15. Tu T, Bühler S, Bartenschlager R (2017) Chronic viral hepatitis and its association with liver cancer. Biol Chem 398(8): 817-837.

16. Goedert JJ (2016) Effects of HIV, Immune Deficiency, and Confounding on the Distal Gut Microbiota. EBioMedicine 5: 14-15.

17. Katzelnick LC, Coloma J, Harris E (2017) Dengue: knowledge gaps, unmet needs, and research priorities. Lancet Infect Dis 17(3): e88-e100.

18. Wang Z, Wang P, An J (2016) Zika virus and Zika fever. Virol Sin 31(2): 103-109.

\section{ISSN: 2574-1241}

DOI: $10.26717 /$ BJSTR.2020.24.004040

Thaís Cristine Pereira. Biomed J Sci \& Tech Res

This work is licensed under Creative Commons Attribution 4.0 License

Submission Link: https://biomedres.us/submit-manuscript.php
19. Musso D, Nilles EJ, Cao-Lormeau VM (2014) Rapid spread of emerging Zika virus in the Pacific area. Clin Microbiol Infect 20(10): 0595-0596.

20. Hua C, Combe B (2017) Chikungunya Virus-Associated Disease. Curr Rheumatol Rep 19(11): 69.

21. Mota MT, Terzian AC, Silva ML, Estofolete C, Nogueira ML (2016) Mosquito-transmitted viruses - the great Brazilian challenge. Braz J Microbiol 1: 38-50.

22. do Rosário MS, de Jesus PA, Vasilakis N, Farias DS, Novaes MA, et al. (2016) Guillain-Barré Syndrome After Zika Virus Infection in Brazil. Am J Trop Med Hyg 95(5): 1157-1160.

23. Nóbrega MEBD, Araújo ELL, Wada MY, Leite PLE, Dimech GS, et al. (2018) Outbreak of Guillain-Barré syndrome possibly related to prior Zika virus infection,Metropolitan Region of Recife, Pernambuco, Brazil, 2015. Epidemiol Serv Saude 27(2): e2017039.

24. Keesen TSL, de Almeida RP, Gois BM, Peixoto RF, Pachá ASC, et al. (2017) Guillain-Barré syndrome and arboviral infection in Brazil. Lancet Infect Dis 17(7): 693-694.

25. Styczynski AR, Malta JMAS, Krow-Lucal ER, Percio J, Nóbrega ME, et al. (2017) Increased rates of Guillain-Barré syndrome associated with Zika virus outbreak in the Salvador metropolitan area, Brazil. PLoS Negl Trop Dis 11(8): e0005869.

26. Cao-Lormeau VM, Blake A, Mons S, Lastère S, Roche C, et al. (2016) Guillain-Barré syndrome outbreak associated with Zika virus infection in French Polynesia: a case-control study. Lancet 387(10027): 15311539.

27. Qureshi NK, Begum A, Saha PR, Hossain MI (2012) Guillain-Barre syndrome following dengue fever in adult patient. J Med 13: 246-249.

28. Cerny T, Schwarz M, Schwarz U, Lemant J, Gérarin P, et al. (2017) The range of neurological complications at chikungunya fever. Neurocrit Care 27 (3): 447-457.

29. Vieira MADCES, Costa CHN, Linhares ADC, Borba AS, Henriques DF, et al. (2018) Potential role of dengue virus, chikungunya virus and Zika virus in neurological diseases. Mem Inst Oswaldo Cruz 113(11): e170538.

30. Van der Meche FG, Schmitz, PI (1992) A randomized trial comparing intravenous immune globulin and plasma exchange in Guillain-Barre syndrome. Dutch Guillain-Barre Study Group. N Engl J Med 326(17): 1123-1129.

31. Hughes RA, Swan AV, van Doorn PA (2014) Intravenous immunoglobulin for Guillain-Barré syndrome. Cochrane Database Syst Rev 2014(9): CD002063.

32. Verboon C, van Doorn PA, Jacobs BC (2017) Treatment dilemmas in Guillain-Barré syndrome. J Neurol Neurosurg Psychiatry 88(4): 346352.

33. Iagaru N, Cinteza E, Cochino AV (2007) Adverse Effects of Immunoglobulin Therapy. Maedica-a J Clin Med 2 (4).

34. Murdaca G, Colombo BM, Puppo F (2011) Emerging biological drugs: A new therapeutic approach for systemic lupus erythematosus. An update on effectiveness and adverse events. Autoimune Rev 11(1): 56-60.

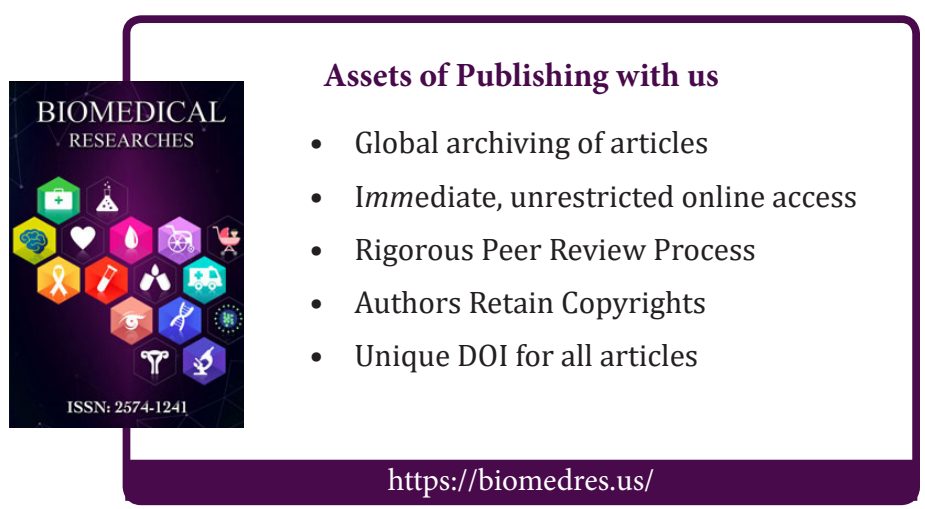

